\title{
Intra-spinal epidural leakage of bone cement during vertebroplasty of an osteoporotic vertebral fracture: case report and review of literature
}

\author{
Tushar N. Rathod, Kunal A. Shah*, Chetan Shende
}

Department of Orthopedics, Seth G. S. Medical College and KEM Hospital, Mumbai, Maharashtra, India

Received: 05 September 2019

Revised: 12 October 2019

Accepted: 14 October 2019

*Correspondence:

Dr. Kunal A. Shah,

E-mail: kunalajitshah@gmail.com

Copyright: () the author(s), publisher and licensee Medip Academy. This is an open-access article distributed under the terms of the Creative Commons Attribution Non-Commercial License, which permits unrestricted non-commercial use, distribution, and reproduction in any medium, provided the original work is properly cited.

\begin{abstract}
Vertebral fractures are one of the most common complications of osteoporosis. Prolonged and intractable pain leads to immobilization and significant morbidity. Vertebroplasty is designed primarily to relieve pain, and the procedure is considered when osteoporotic vertebral fracture does not respond to a reasonable period of conservative care. Vertebroplasty has a low complication rate with most common complication being adjacent vertebral body fracture and rare complication due to extra-vertebral cement leakage causing nerve root compression or pulmonary embolism. We report a case of 55 year old lady with osteoporotic D12 wedge compression fracture subjected to vertebroplasty resulting in intraspinal cement leakage noticed intra-operatively. Patient underwent immediate decompression, cement extraction and posterior instrumentation. Postoperative course was uneventful.
\end{abstract}

Keywords: Vertebroplasty, Cement leakage, Osteoporotic vertebral fractures, Kyphoplasty

\section{INTRODUCTION}

Cement vertebroplasty is an effective treatment of osteoporotic vertebral fractures in elderly. It is performed percutaneously under fluoroscopic guidance during which polymethylmethacrylate (PMMA) cement is injected into the collapsed vertebral body. ${ }^{1,2}$ Although leakage of cement during the procedure is a rare complication, it is devastating. Operating surgeons have always been in dilemma regarding decision for surgical intervention in such cases due to paucity of literature. ${ }^{1}$ We report a case of intra-spinal epidural cement leakage during vertebroplasty and its management with short review on prevention and treatment.

\section{CASE REPORT}

A 55 year old post-menopausal woman was referred to our hospital in May 2019 with alleged history of fall one year back and back pain localized to fracture site. She had no neurological deficit. Clinically, deep tenderness was noted at $12^{\text {th }}$ dorsal (D) vertebral level with paraspinal muscle spasm. X-ray of thoracolumbar spine suggested anterior wedge compression fracture of D12 vertebra with osteoporotic and degenerative changes (Figure 1). MRI of dorsal spine showed features of osteoporotic anterior wedge compression fracture of D12 vertebral body with effacement of anterior thecal sac without any neural foramen and spinal canal compromise with disc desiccation at all levels.

Percutaneous vertebroplasty was performed under general anesthesia in prone position under fluoroscopic guidance. Medtronic KYPHON V Vertebroplasty kit ${ }^{\circledR}$ with osteo-introducer $11 \mathrm{G}$ trocar was used. Percutaneously $11 \mathrm{G}$ trocar was introduced fluoroscopically starting close to the lateral wall of pedicle of D12 vertebra. Entry was taken from right 
pedicle of D12 vertebra. Needle advanced towards the anterior half of vertebral body without breaching the medial wall. Three ml of PMMA cement was injected in D12 vertebra from right pedicle under fluoroscopic guidance. After 30 seconds of injection extravasation of cement was noted along posterior border of D12 and L1 vertebral body extending into the canal. Immediate decompression with laminectomy of D12 and L1 level was performed by posterior midline approach. Cement extravasation noted along right paracentral area of canal. Cement extraction was done with burr and kerrison's rongeur. No intradural cement extravasation was noted. Due to adhesion of cement, dural sheath tear occurred near right D11 nerve root which was irreparable. Dural tear underneath D12 lamina was repaired with monofilament non absorbable polypropylene 4-0 suture. As significant compression or dural damage was not found, further exploration and decompression for extravasated cement was not done. Posterior instrumentation with pedicle screws for D11, D12 and L1 vertebral level was done with posterolateral fusion from D11-L1 vertebral level (Figure 2). Subfascial passive suction drain was placed. Post operatively patient was kept in prone position for 5 days with foot end of bed raised. Full weight bearing mobilization was started on $7^{\text {th }}$ day without any orthosis. No neurological deficit was noted and back pain improved significantly. Postoperative CT scan of dorsolumbar spine showed cement filling the right side of D12 vertebral body, right pedicle and leaked cement extending into anterior epidural space at D11 level. Extravasated cement extruded in anterior epidural space on right side proximally upto infra-pedicular level of D11 vertebra (Figure 3). Distally it extruded upto supra-pedicular level of L1 vertebra. Patient recovered uneventfully and was discharged two weeks later after suture removal.

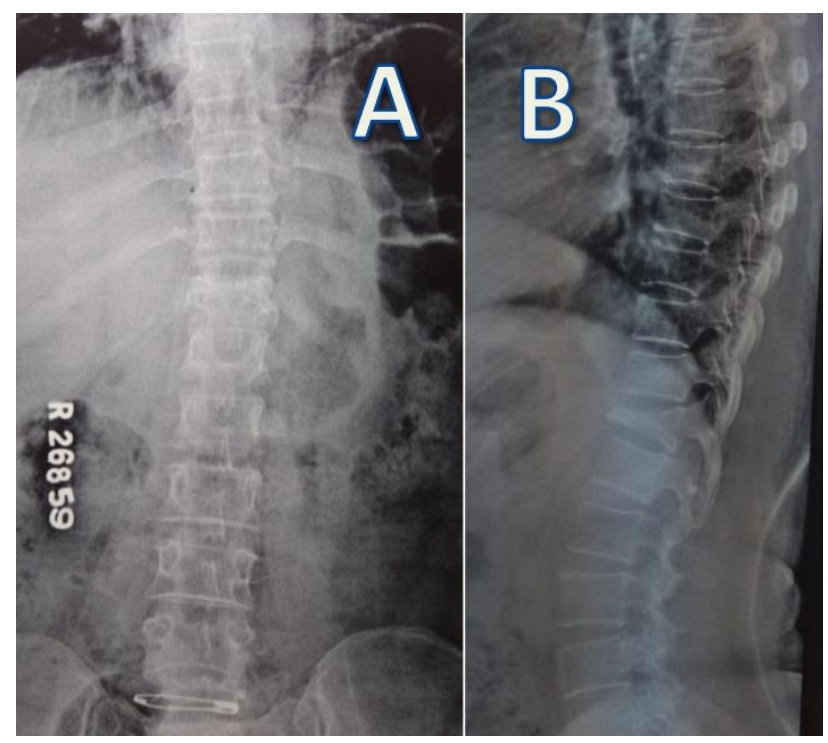

Figure 1 (A and B): Preoperative X-ray showing anterior wedge compression fracture of dorsal 12th vertebra.

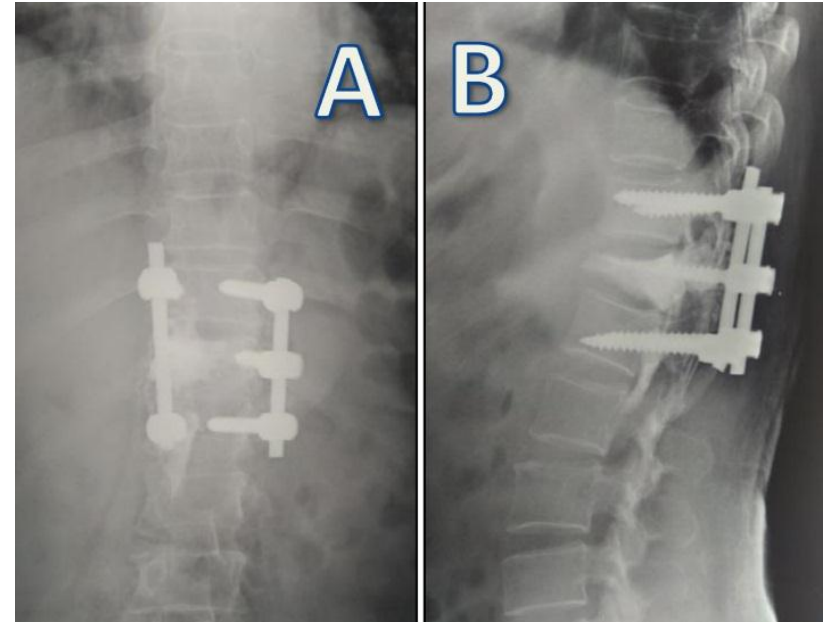

Figure 2 (A and B): Postoperative X-ray showing posterior pedicular screw instrumentation (D11 to L1) and fusion.

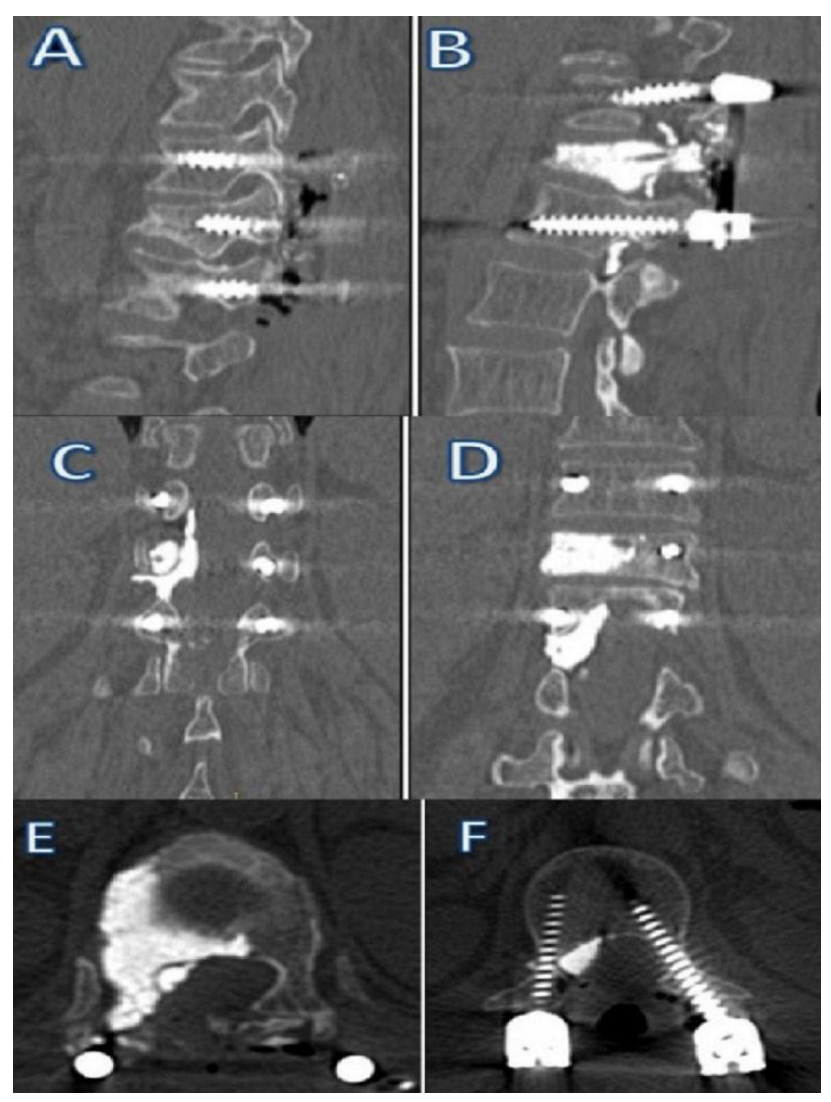

Figure 3: Postoperative CT scans showing extrusion of cement into (A) sagittal section with no cement on left side; (B) sagittal section on right side with cement filling the body, pedicle and extrusion in the spinal

canal; (C) coronal section of posterior part with extrusion seen in the spinal canal; (D) coronal section of anterior part showing cement filling in the body;

(E) axial cut of CT scan at Dorsal 12th verterbra showing cement in right side of body and extrusion in right side of canal; (F) axial cut of CT scan at Lumbar 1st verterbra showing cement extrusion in right side of canal. 


\section{DISCUSSION}

Vertebral compression fractures (VCF) secondary to osteoporosis occur in up to $20 \%$ of patients more than 50 years of age. They are major cause of morbidity in elderly population. It includes chronic pain due to nonunion and spinal deformity. Kyphotic deformity due to dorsal VCF shifts the center of gravity anteriorly, resulting in increased bending moment at the apex and progressive deformity. ${ }^{3}$ The risk of a new vertebral fracture within 1 year of a VCF is 5 to 25 times. $^{4,5}$ Therefore, the osteoporotic VCF should not only be treated for pain management but also to prevent subsequent vertebral fractures. Vertebroplasty provides immediate stability and rapid pain relief with early mobilization and prevents complications of long term immobilization. There is a low incidence of clinically significant complications. ${ }^{6}$ Most of the complications result from cement extravasation, embolization, and adjacent vertebral fractures. Asymptomatic cement extravasation has been observed clinically in up to $72 \%$ of patients and by post procedure CT in $88 \%$ of patients undergoing vertebroplasty. ${ }^{7}$ Epidural leakage of cement is more common than expected and subclinical leaks go undetected unless a postoperative CT scan is done. The most severe complication is motor weakness of lower extremities and bowel bladder disturbances. Neurological deficit can occur due to mechanical compression or thermal injury during exothermic phase due to intra spinal leakage. ${ }^{8}$ The most common site of leakage is the endplate or disc $(45 \%)$, paravertebral $(35 \%)$, epidural $(20 \%)$, and prevertebral $(18 \%) .{ }^{9}$ It is reported that complete filling of vertebral body is not necessary to achieve relief from pain and there are more chances of epidural leak if injected in posterior part of vertebral body than anterior. Also, more cement leaks were reported by bi-pedicular approach than single pedicle approach. ${ }^{8}$ Yeom et al classified the pattern of cement leakage in vertebroplasty based on radiographic analysis into type B (leakage via basivertebral vein), type $\mathrm{S}$ (leakage via segmental vein), type $\mathrm{C}$ (through the cortical defect). ${ }^{10}$ Genant et al described the classification of severity of vertebral fractures according to percentage of vertebral body collapse into mild $(20-25 \%)$, moderate $(26-40 \%)$ and severe (>40\%). High fracture severity grade with low viscosity of cement, cortical disruption and excessive injection pressure are risk factors for cement leakage. Intra spinal leakage is a known complication. ${ }^{11}$ There is no significant difference in the cement leakage rate between burst and compression fractures. $^{12}$ Cement leakage in our patient was predominantly on right side of spinal canal and migrated superiorly and inferiorly along medial wall of pedicle.

Vertebroplasty and kyphoplasty are two minimal invasive percutaneous cement augmentation techniques to address pain and deformity in VCF. Both involve percutaneous cement injection into a fractured vertebral body. Reduction of fractured vertebral body is not done in vertebroplasty, while kyphoplasty involves the percutaneous insertion of an inflatable bone tamp which elevates the endplate and restores the vertebral body height while creating a cavity to be filled with PMMA. In a meta-analysis performed by Han et al for comparing vertebroplasty and kyphoplasty, results demonstrated no difference in long-term pain relief or functional outcomes between the two techniques. ${ }^{13}$ Similarly Omidi et al demonstrated no difference between the two in singlelevel osteoporotic VCFs. ${ }^{14}$ A systematic review and meta-analysis of RCTs and nonrandomized studies comparing vertebroplasty to kyphoplasty demonstrated no difference between the two methods of cement augmentation with regard to pain and disability outcomes in short and long term. ${ }^{15}$

Certain precautions to be taken during the procedure areadequate opacification of cement, preventing breach in the medial wall of pedicle, continuous fluoroscopic monitoring during injection, stopping injection of cement when it reaches posterior fourth of vertebral body and intermittent release of injection pressure. Overaggressive or complete filling of body should be avoided. Greater injection pressure applied at the end of procedure as the cement become harder could be the reason for leakage in our patient. To avoid this complication, high viscosity cement should be injected under controlled low pressure. It is recommended by Harrington et al, that local anesthesia should be preferred over general anesthesia with the rationale of easier clinical detection of neurological compromise in a conscious patient. ${ }^{2}$

Immediate decompression with removal of bone cement will help to prevent or revert a new onset neurological deficit if the cause is mechanical compression. Surgical exploration and removal of bone cement in the anterior epidural space, intervertebral foramina, intradural anteriorly or mixed with cauda equina nerve roots is difficult. ${ }^{1}$ In our case, we surgically decompressed by removing the cement in the anterior epidural space. We repaired the dural tear and fused D10 - D12 vertebra with instrumentation and bone grafting.

\section{CONCLUSION}

Cement vertebroplasty is effective in treating osteoporotic VCFs. Leakage of cement can have serious consequences. Decision making for surgical management is challenging. Prevention of complications by taking necessary precautions and pre-operative identifications of risk factors for cement leakage is important. Avoiding use of low viscosity cement, controlled pressure of injection and continuous fluoroscopy is advised. Prompt exploration, decompression and cement removal should be done in significant leakage.

\section{Funding: No funding sources Conflict of interest: None declared Ethical approval: Not required}




\section{REFERENCES}

1. Teng MMH, Cheng H, Ho DMT, Chang CY. Intraspinal leakage of bone cement after vertebroplasty: A report of 3 cases. Am J Neuroradiol. 2006;27:224-9.

2. Harrington KD. Major Neurological Complications Following Percutaneous Vertebroplasty with Polymethylmethacrylate. J Bone Joint Surg Am. 2001;83:1070-3.

3. Belmont PJ, Polly DW, Cunningham BW, Klemme WR. The effects of hook pattern and kyphotic angulation on mechanical strength and apical rod strain in a long-segment posterior construct using a synthetic model. Spine (Phila Pa 1976) 2001;26:627-35.

4. Lau E, Ong K, Kurtz S, Schmier J, Edidin A. Mortality Following the Diagnosis of a Vertebral Compression Fracture in the Medicare Population. J Bone Jt Surgery-American Vol. 2008;90:1479-86.

5. Haczynski J, Jakimiuk A. Vertebral fractures: a hidden problem of osteoporosis. Med Sci Monit. 2001;7:1108-17.

6. Pateder DB, Khanna AJ, Lieberman IH. Vertebroplasty and Kyphoplasty for the Management of Osteoporotic Vertebral Compression Fractures. Orthop Clin North Am. 2007;38:409-18.

7. Klazen CA, Lohle PN, de Vries J, Jansen FH, Tielbeek AV, Blonk MC, et al. Vertebroplasty versus conservative treatment in acute osteoporotic vertebral compression fractures (Vertos II): an openlabel randomised trial. Lancet. 2010;376:1085-92.

8. Ryu KS, Park CK, Kim MC, Kang JK. Dosedependent epidural leakage of polymethylmethacrylate after percutaneous vertebroplasty in patients with osteoporotic vertebral compression fractures. J Neurosurg. 2002;96:56-61.

9. Martin DJ, Rad AE, Kallmes DF. Prevalence of extravertebral cement leakage after vertebroplasty: procedural documentation versus CT detection. Acta Radiol 2012;53:569-72.

10. Yeom JS, Kim WJ, Choy WS, Lee CK, Chang BS, Kang JW. Leakage of cement in percutaneous transpedicular vertebroplasty for painful osteoporotic compression fractures. J Bone Joint Surg Br. 2003;85:83-9.

11. Genant HK, Wu CY, van Kuijk C, Nevitt MC. Vertebral fracture assessment using a semiquantitative technique. J Bone Miner Res 2009;8:1137-48.

12. Li C-H, Chang M-C, Liu C-L, Chen T-S. Osteoporotic burst fracture with spinal canal compromise treated with percutaneous vertebroplasty. Clin Neurol Neurosurg. 2010;112:678-81.

13. Han S, Wan S, Ning L, Tong Y, Zhang J, Fan S. Percutaneous vertebroplasty versus balloon kyphoplasty for treatment of osteoporotic vertebral compression fracture: a meta-analysis of randomised and non-randomised controlled trials. Int Orthop. 2011;35:1349-58.

14. Omidi-Kashani F, Samini F, Hasankhani EG, Kachooei AR, Toosi KZ, Golhasani-Keshtan F. Does Percutaneous Kyphoplasty Have Better Functional Outcome Than Vertebroplasty in Single Level Osteoporotic Compression Fractures? A Comparative Prospective Study. J Osteoporos 2013;2013:1-5.

15. Gu CN, Brinjikji W, Evans AJ, Murad MH, Kallmes DF. Outcomes of vertebroplasty compared with kyphoplasty: a systematic review and meta-analysis. J Neurointerv Surg. 2016;8:636-42.

Cite this article as: Rathod TN, Shah KA, Shende C. Intra-spinal epidural leakage of bone cement during vertebroplasty of an osteoporotic vertebral fracture: case report and review of literature. Int J Res Orthop 2019;5:1222-5. 